\title{
Fabrication of transparent self-supporting alumina films by homogeneous precipitation process
}

\author{
Kazuhiro INOUE, Hidemi KUREBAYASHI, Masachika HAMA, \\ Yoshio KOBAYASHI, ${ }^{\dagger}$ Yusuke YASUDA* $^{*}$ and Toshiaki MORITA* \\ Department of Biomolecular Functional Engineering, College of Engineering, Ibaraki University, \\ 4-12-1 Naka-narusawa-cho, Hitachi, Ibaraki 316-8511, Japan \\ *Hitachi Research Laboratory, Hitachi Ltd., 7-1-1 Omika-cho, Hitachi, Ibaraki 319-1292, Japan
}

\begin{abstract}
This paper reports fabrication of transparent self-supporting alumina films by using homogeneous precipitation and peptization processes. White precipitate of aluminum hydroxide was prepared with a homogeneous precipitation method using aluminum nitrate and urea in aqueous solution. The obtained aluminum hydroxide precipitate was peptized by using acetic acid at room temperature, which resulted in production of a transparent alumina sol. The alumina sol was transformed to an alumina gel film by drying the sol at room temperature. The alumina film was amorphous or fine crystallites even after annealed at a temperature as high as $5_{00}^{\circ} \mathrm{C}$, and was crystallized to $\gamma-\mathrm{Al}_{2} \mathrm{O}_{3}$ at $900^{\circ} \mathrm{C}$.

(C)2013 The Ceramic Society of Japan. All rights reserved.
\end{abstract}

Key-words : Alumina, Aluminum salt, Film, Homogeneous precipitation method, Sol-gel

[Received December 5, 2012; Accepted March 23, 2013]

\section{Introduction}

Transparent films are available for fabricating materials in optoelectronics such as an optical filter and an antireflection film. ${ }^{1)-3)}$ Representative materials for the transparent thin films are silica, titania, indium tin oxide, and alumina. The films can be more functioned with incorporation of functional materials such as laser dyes, rare earth, and semiconductor into the films. ${ }^{4)-7)}$ Since the alumina has high thermal conductivity among them, ${ }^{8)}$ the functional materials will be thermally stabilized with their incorporation into the alumina films.

Several methods for fabricating films have been proposed. They are roughly classified into two groups. One is methods performed in gas phase, in which chemical vapor deposition and physical vapor deposition have been extensively studied.9),10) This method is limited to production the films on substrate. Another is methods performed in liquid phase, in which solgel methods and spray-coating are representative. ${ }^{11)-13)}$ Among them, the sol-gel method is a good candidate as a future process, because it is a low-temperature synthesis method that does not require large scale equipments and it is easy to attain homogeneous compositions. ${ }^{14-16)}$ In addition, the sol-gel method can be used for more general needs for fabrication of films, since selfsupporting films can be also fabricated by the method.

The alumina films can be also fabricated with the sol-gel method. Most sol-gel methods for alumina fabrication use alkoxide as a starting material. ${ }^{17-19)}$ Though they can fabricate alumina films, the main difficulty for the use of the alkoxide arises from its high cost. It can be noted as another difficulty that alcohol produced with hydrolysis of the alkoxide is remained in the film, which deteriorates function of the film. Apart from the alkoxide, aluminum salt may be also considered as a source of aluminum, and is available at low cost compared with the

\footnotetext{
Corresponding author: Y. Kobayashi; E-mail: ykoba@mx.ibaraki. ac.jp
}

alkoxide. From this view point, Kurokawa et al. has proposed a method for producing alumina films by using aluminum salts. ${ }^{20)}$ In the method, aluminum hydroxide is precipitated with the addition of base to an aluminum salt aqueous solution, then it is peptized with acid to produce alumina sol, and finally the alumina sol is converted to an alumina film with gelation that takes place with drying. Though this method works well on the film fabrication, the peptization is performed by refluxing the aluminum hydroxide precipitate at ca. $80^{\circ} \mathrm{C}$ for a period as long as several hours, which provides a complication of procedures. A homogeneous precipitation method is alternative for preparing aluminum hydroxide precipitate. In the homogeneous precipitation method, precipitators such as urea are decomposed at high temperature, which increases $\mathrm{pH}$ of solution slowly and homogeneously. As a result, fine particles are produced. In a preliminary experiment, aluminum hydroxide precipitate prepared by a homogeneous precipitation method could be peptized at room temperature. It was speculated the precipitate particles were so fine that the peptization took place with no heating. Accordingly, to simplify procedures for peptization, the homogeneous precipitation method is promising for preparing aluminum hydroxide precipitate. In addition, alumina sol prepared from fine aluminum hydroxide precipitate particles is expected to be converted to high quality alumina films.

In the present work, a method using the aluminum hydroxide precipitate prepared with the homogeneous precipitation method using aluminum salt as starting material is proposed for preparing alumina sol. Transparent self-supporting alumina films were fabricated by using the alumina sol, and their characteristics of transparency and crystallinity were investigated.

\section{Experimental}

\subsection{Chemicals}

Aluminum nitrate enneahydrate $\left[\mathrm{Al}\left(\mathrm{NO}_{3}\right)_{3} \cdot 9 \mathrm{H}_{2} \mathrm{O}\right](98.0 \%)$ and urea $(99.0 \%)$ were used as a starting material for aluminum hydroxide and a precipitation-inducer for preparation of alumi- 
num hydroxide, respectively. Acetic acid $(99.7 \%)$ was used as a peptizer for aluminum hydroxide. All chemicals were purchased from Kanto Chemical Co., Inc., and were used as received. Water that was ion-exchanged and distilled with Yamato WG-250 was used in all the preparations.

\subsection{Preparation}

Precipitate of aluminum hydroxide was prepared by the homogeneous precipitation method. The preparation was carried out at initial concentrations of $2-7 \mathrm{M}$ urea and $0.2 \mathrm{M} \mathrm{Al}\left(\mathrm{NO}_{3}\right)_{3}$ in a hermetically sealed flask reactor under stirring at $80^{\circ} \mathrm{C}$ for $0-10 \mathrm{~h}$. The obtained white precipitate was aged for $12 \mathrm{~h}$ after the preparation. The aged precipitate was washed by repeating centrifugation, removal of supernatant, addition of the water and sonication over three times. The washed precipitate was peptized at 25 (room temperature) and $80^{\circ} \mathrm{C}$ with the addition of acetic acid at $[\mathrm{acid}] /\left[\mathrm{Al}^{3+}\right]$ molar ratios of $0-0.25$, which produced a sol (alumina sol). The sol was casted onto a petri dish, and dried in air at room temperature. Then, the sol was converted to a gel film (alumina film). The films were pulverized with a mortar into powder, and then annealed in air at various temperatures.

\subsection{Characterization}

The samples were characterized by ultraviolet (UV)-visible (VIS) spectroscopy, thermal analysis (TG-DTA) and X-ray diffractometry (XRD). UV-VIS extinction spectra were measured with a Hitachi UV-3010 spectrophotometer using a quartz cuvette with a light-path length of $1 \mathrm{~cm}$. TG-DTA was performed in air at a heating rate of $10^{\circ} \mathrm{C} / \mathrm{min}$ with a Seiko SSC5200 thermal analyzer. Powder, which was obtained by pulverizing alumina film with a mortar, was used as samples for TG-DTA measurements. XRD measurements were carried out with a Rigaku RAD-B X-ray diffractometer at $50 \mathrm{kV}$ and $150 \mathrm{~mA}$ with $\mathrm{CuK} \alpha_{1}$ radiation. Samples for XRD measurements were obtained in the same manner as that for the TG-DTA samples.

\section{Results and discussion}

\subsection{Alumina sol}

\subsubsection{Effect of urea concentration}

Figure 1 shows dependences of the $\mathrm{pH}$ of $\mathrm{Al}\left(\mathrm{NO}_{3}\right)_{3}$ aqueous solution in reaction time at various urea concentrations. When the concentration was $2 \mathrm{M}$, the $\mathrm{pH}$ was almost constant at 3 , and the solution was still transparent, even after $10 \mathrm{~h}$. For 5 and $7 \mathrm{M}$, the $\mathrm{pH}$ values began to increase after $2 \mathrm{~h}$, then achieved around 10 at $10 \mathrm{~h}$, and finally saturated at the $\mathrm{pH}$ of 10 . A rate for the $\mathrm{pH}$ increase was lager at $7 \mathrm{M}$ than that for $5 \mathrm{M}$ due to the large

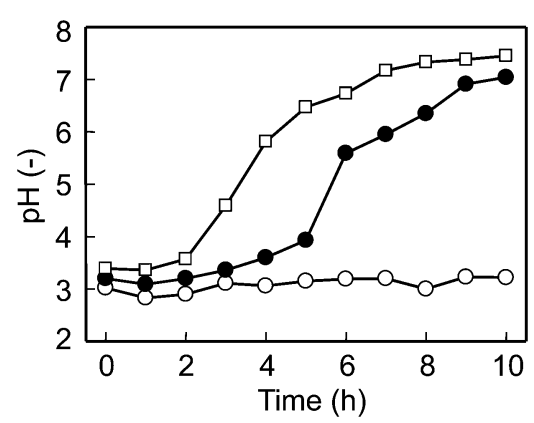

Fig. 1. pHs of $\mathrm{Al}\left(\mathrm{NO}_{3}\right)_{3}$ aqueous solutions in homogeneous precipitation method using urea as a function of reaction time. The urea concentrations were $2(\bigcirc), 5(\bigcirc)$, and $7(\square) \mathrm{M}$. urea concentration. During the $\mathrm{pH}$ increases, the solutions became opaque, and then white precipitates were sedimented. The sedimentation was remarkable for $7 \mathrm{M}$, compared with that for $5 \mathrm{M}$. The increase in urea concentration leads to an increase in the ionic strength in the solution. Since an increase in the ionic strength compresses double layer on solid materials such as colloidal particles, ${ }^{21)}$ the double layer repulsion between aluminum hydroxide particles was probably reduced at the high urea concentration. Thus, at the high urea concentration, aluminum hydroxide particles probably aggregated, because of the reduced double layer repulsion. Consequently, the aluminum hydroxide aggregates were remarkably sedimented at the high urea concentration.

\subsubsection{Effect of peptization temperature}

Peptization of the aluminum hydroxide precipitate was performed by adding acetic acid. According to the previous work using aluminum hydroxide precipitate prepared by adding ammonia aqueous solution as a precipitator to aluminum salt aqueous solution, ${ }^{20)}$ the precipitate becomes transparent by performing peptization at $80^{\circ} \mathrm{C}$. With the respect to the present work, the precipitate became also a transparent sol by peptizing at $80^{\circ} \mathrm{C}$. Peptization temperature is desired to be lowered for simplifying preparation processes. In the present work, peptization was performed at a temperature as low as $25^{\circ} \mathrm{C}$. As a result, a transparent sol was also produced, though it took longer time to obtain the transparent sol compared to that for the peptization temperature of $80^{\circ} \mathrm{C}$. The slow and homogeneous increase in $\mathrm{pH}$ of solution through decomposition of urea probably produced fine aluminum hydroxide particles. Since the fine particles were expected to be easily peptized, the precipitate was successfully peptized at the low temperature.

\subsubsection{Effect of peptization time}

Figure 2 shows transmittance of alumina sols as a function of peptization time. The measurements were performed at 500 $\mathrm{nm}$. The transmittance increased with an increase in the peptization time, and it almost leveled off over $6 \mathrm{~h}$. Accordingly, in the present work, all the alumina sols except for the sols produced in this section were prepared with the peptization time of $12 \mathrm{~h}$ to complete the peptization.

\subsubsection{Effect of acetic acid concentration}

Figure 3 shows transmittance of alumina sols produced by peptizing the aluminum hydroxide precipitate at different concentrations of acetic acid. The measurements were also performed at $500 \mathrm{~nm}$. Alumina sol was still opaque at $[$ acid $] /\left[\mathrm{Al}^{3+}\right]$ molar ratios of 0 and 0.05 . The sol became transparent at 0.10 , and the transmittance was almost constant over 0.10 . The transmittance was achieved $96.4 \%$ at 0.20 . Possibly, a size of particles in the

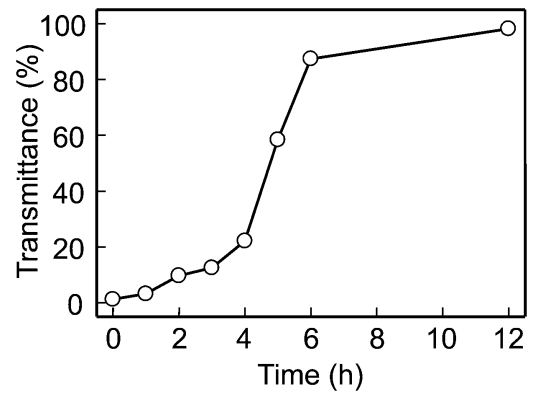

Fig. 2. Transmittance of alumina sol vs. peptization time. The transmittances were measured at a wavelength of $500 \mathrm{~nm}$. The aluminum hydroxide used was prepared at the urea concentration of $5 \mathrm{M}$. The [acid]/ $\left[\mathrm{Al}^{3+}\right]$ molar ratio was 0.15 , and the peptization temperature was $25^{\circ} \mathrm{C}$. 


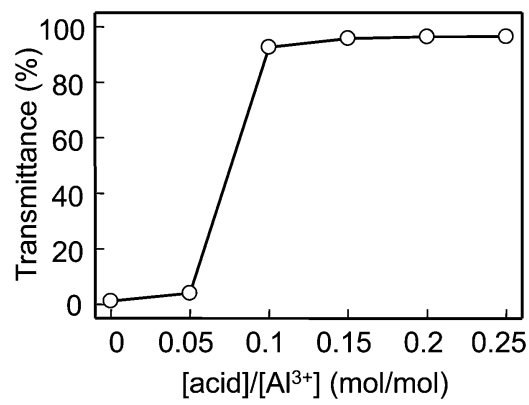

Fig. 3. Transmittance of alumina sol vs. $[$ acid $] /\left[\mathrm{Al}^{3+}\right]$ molar ratio. The transmittances were measured at a wavelength of $500 \mathrm{~nm}$. The aluminum hydroxide used was prepared at the urea concentration of $5 \mathrm{M}$. The temperature and time of peptization were $25^{\circ} \mathrm{C}$ and $12 \mathrm{~h}$, respectively.

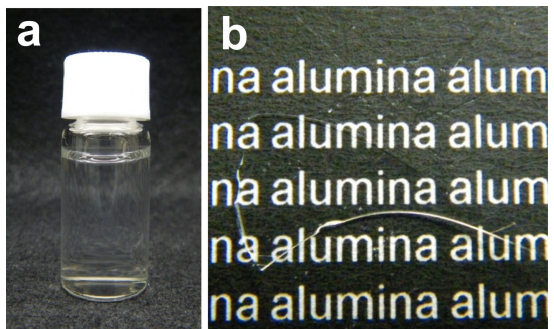

Fig. 4. Photographs of alumina sol (a) and alumina film (b). Aluminum hydroxide, which was prepared at the urea concentration of $5 \mathrm{M}$, was used for preparing the alumina sol. The aluminum hydroxide was peptized at $25^{\circ} \mathrm{C}$ for $12 \mathrm{~h}$ for producing the alumina sol that was used for fabricating the alumina film.

alumina sol was so small compared to wavelength in visible range that light scattering did not strongly take place; The peptization was successfully performed over 0.10 , and consequently the transparent alumina sol was prepared.

Figure 4(a) shows a photograph of the alumina sol that was obtained with the optimized reaction conditions; The urea concentration was $5 \mathrm{M}$, the $[\mathrm{acid}] /\left[\mathrm{Al}^{3+}\right]$ molar ratio was 0.15 , and the temperature and time of peptization were $25^{\circ} \mathrm{C}$ and $12 \mathrm{~h}$, respectively. The obtained alumina sol appeared very transparent.

\subsection{Alumina film}

\subsubsection{Gelation of alumina sol}

The transparent alumina sol was gelated by drying it in air at room temperature, and then an alumina film was produced. Figure 4(b) shows a photograph of the alumina film. The film was as transparent as that for the alumina sol, and no precipitation or no flocculation was observed in the film, which indicated that the alumina sol obtained was colloidally stable.

\subsubsection{Effect of annealing}

Figure 5 shows TG-DTA curves for the as-prepared alumina film. A weight loss accompanying an endothermic peak was detected at ca. $100^{\circ} \mathrm{C}$, which was attributed to liberation of water. Another weight loss accompanying an endothermic peak was detected at $215^{\circ} \mathrm{C}$. According to previous works studying on aluminum hydroxide, ${ }^{22), 23)}$ the loss at $215^{\circ} \mathrm{C}$ was attributed to elimination of $\mathrm{H}_{2} \mathrm{O}$ from $\mathrm{Al}(\mathrm{OH})_{3}$. At $389^{\circ} \mathrm{C}$, a weight loss with a strong exothermic peak appeared, which was due to decomposition of acetic acid used for peptization. An exothermic peak with no weigh change was obtained at $862^{\circ} \mathrm{C}$. This result implied that the alumina film was crystallized at $862^{\circ} \mathrm{C}$, because weight loss does not take place in crystallization in general.

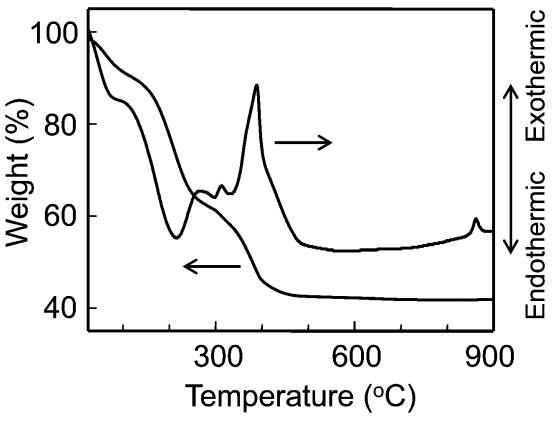

Fig. 5. TG-DTA curves of alumina film. The measurement was performed in air at a heating rate of $10^{\circ} \mathrm{C} / \mathrm{min}$.

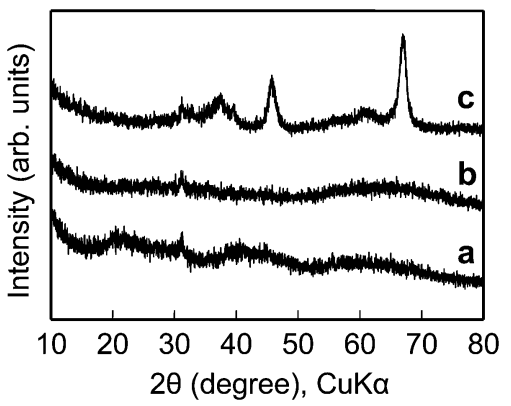

Fig. 6. XRD patterns of alumina films annealed at temperatures of (a) 25 (as-prepared), (b) 500 , and (c) $900^{\circ} \mathrm{C}$.

Figure 6 shows XRD patterns of alumina films annealed at various temperatures. In the as-prepared alumina film, a few peaks that were roughly assigned to those of pseudoboehmite were detected around 15, 30, and 40 degree, according to the reference. ${ }^{24)}$ These peaks were broad and diffuse, which indicated that the films were more or less amorphous or crystallites that were too fine to be detected. No dominant peaks appeared even for annealing at a temperature as high as $500^{\circ} \mathrm{C}$, which indicated that the alumina was quite stable in the states such as amorphous or fine crystallite. For $900^{\circ} \mathrm{C}$, peaks attributed to $\gamma-\mathrm{Al}_{2} \mathrm{O}_{3}$ (JCPDS card \#29-0063) appeared at 37.5, 45.8 and $66.8^{\circ}$. This result revealed that transformation from poorly crystallized pseudoboehmite to $\gamma-\mathrm{Al}_{2} \mathrm{O}_{3}$ crystallites took place, which supported the implication obtained in the thermal analysis for the crystallization of alumina at $862^{\circ} \mathrm{C}$. There was no large difference in the XRD patterns between the alumina films fabricated by Kurokawa et al. ${ }^{20)}$ and in the present work; The alumina films similar to those for Kurokawa et al.'s work were successfully fabricated with no heating the aluminum hydroxide precipitate for peptization in the present work.

\section{Conclusions}

The transparent alumina films were fabricated from aluminum salt as a starting material. A homogeneous precipitation method using aluminum nitrate and urea in aqueous solution was performed for producing the white precipitates of aluminum hydroxide. The transparent alumina sol was successfully produced by the peptization of the aluminum hydroxide with the addition of acetic acid even at the temperature as low as $25^{\circ} \mathrm{C}$ (room temperature). Drying the sol at room temperature resulted in the production of the transparent alumina gel film. The alumina film was amorphous or fine crystallites even after annealed at a temperature as high as $500^{\circ} \mathrm{C}$, and was crystallized to $\gamma-\mathrm{Al}_{2} \mathrm{O}_{3}$ by annealing at $900^{\circ} \mathrm{C}$. 


\section{References}

1) T. Ootsuka, Z. Liu, M. Osamura, Y. Fukuzawa, R. Kuroda, Y. Suzuki, N. Otogawa, T. Mise, S. Wang, Y. Hoshino, Y. Nakayama, H. Tanoue and Y. Makita, Thin Solid Films, 476, 30-34 (2005).

2) K. M. A. Sobahan, Y. J. Park, J. J. Kim and C. K. Hwangbo, Opt. Commun., 284, 873-876 (2011).

3) C. Shou, Z. Luo, T. Wang, W. Shen, G. Rosengarten, W. Wei, C. Wang, M. Ni and K. Cen, Appl. Energy, 92, 298-306 (2012).

4) A. V. Deshpande and U. Kumar, J. Lumin., 130, 839-844 (2010).

5) J. L. Ferrari, K. O. Lima, L. J. Q. Maia and R. R. Gonçalves, Thin Solid Films, 519, 1319-1324 (2010).

6) Z. Xiao, B. Zhou, L. Yan, F. Zhu, F. Zhang and A. Huang, Phys. Lett. A, 374, 1297-1300 (2010).

7) P. V. Jyothy, K. V. Arun Kumar, S. Karthika, R. Rajesh and N. V. Unnikrishnan, J. Alloys Compd., 493, 223-226 (2010).

8) J. Musil, J. Blažek, P. Zeman, Š. Prokšová, M. Šašek and R. Čerstvý, Appl. Surf. Sci., 257, 1058-1062 (2010).

9) H. Suzuki, H. Araki, M. Tosa and T. Noda, J. Cryst. Growth, 294, 464-468 (2006).

10) A. Schütze and D. T. Quinto, Surf. Coat. Technol., 162, 174182 (2003).

11) Q. Yu, H. Yang, W. Fu, L. Chang, J. Xu, C. Yu, R. Wei, K. Du, H. Zhu, M. Li and G. Zou, Thin Solid Films, 515, 3840-3843 (2007).
12) P. Karasiński, C. Tyszkiewicz, R. Rogoziński, J. Jaglarz and J. Mazur, Thin Solid Films, 519, 5544-5551 (2011).

13) L. Lopez, W. A. Daoud and D. Dutta, Surf. Coat. Technol., 205, 251-257 (2010).

14) X. J. Meng, J. G. Cheng, B. Li, S. L. Guo, H. J. Ye and J. H. Chu, J. Cryst. Growth, 208, 541-545 (2000).

15) Y. J. Yun, J. S. Chung, S. Kim, S. H. Hahn and E. J. Kim, Mater. Lett., 58, 3703-3706 (2004).

16) T. A. Kuriakose, S. N. Kalkura, M. Palanichamy, D. Arivuolid, K. Dierks, G. Bocelli and C. Betzel, J. Cryst. Growth, 263, 517-523 (2004).

17) N. Özer, J. P. Cronin, Y.-J. Yao and A. P. Tomsia, Sol. Energy Mater. Sol. Cells, 59, 355-366 (1999).

18) K. Vanbesien, P. De Visschere, P. F. Smet and D. Poelman, Thin Solid Films, 514, 323-328 (2006).

19) T. Hübert, S. Svoboda and B. Oertel, Surf. Coat. Technol., 201, 487-491 (2006).

20) Y. Kurokawa, T. Shirakawa, S. Saito and N. Yui, J. Mater. Sci. Lett., 5, 1070-1072 (1986).

21) P. A. Kralchevsky, K. D. Danov and E. S. Basheva, Curr. Opin. Colloid Interface Sci., 16, 517-524 (2011).

22) X. Carrier, E. Marceau, J.-F. Lambert and M. Che, J. Colloid Interface Sci., 308, 429-437 (2007).

23) X. Du, X. Su, Y. Wang and J. Li, Mater. Res. Bull., 44, 660665 (2009)

24) W. Cai, H. Li and G. Zhang, J. Phys. Chem. Solids, 71, 515$518(2010)$ 